\title{
EIGHTEENTH ANNUAL CONFERENCE
}

\section{YUCOMAT 2016}

Hunguest Hotel Sun Resort Herceg Novi, Montenegro,

September 5-10, 2016

http://www.mrs-serbia.org.rs

\section{Programme and}

\section{The Book of Abstracts}

Organised by:

Materials Research Society of Serbia

\author{
Endorsed by: \\ Materials Research Society, \\ European Materials Research Society \\ and
}

Federation of European Material Societies 
Title:

THE EIGHTEENTH ANNUAL CONFERENCE YUCOMAT 2016

Programme and The Book of Abstracts

Publisher: $\quad$ Materials Research Society of Serbia

Knez Mihailova 35/IV, P.O.Box 433, 11000 Belgrade, Serbia

Phone: +381 11 2185-437; Fax: + $381112185-263$

http://www.mrs-serbia.org.rs

Editors: $\quad$ Prof. Dr. Dragan P. Uskoković and Prof. Dr. Velimir Radmilović

Technical editor: Aleksandra Stojičić

Cover page: $\quad$ Aleksandra Stojičić and Milica Ševkušić

Front cover: Modified photo by Boby Graham; Flickr

(https://www.flickr.com/photos/libertylittlebasil/76421777774/); CC BY-NC-SA 2.0

Back cover: Modified photo by Magelan Travel; Flickr

(https://www.flickr.com/photos/whltravel/4275855745); CC BY-NC-SA 2.0

Copyright (C) 2016 Materials Research Society of Serbia

Acknowledgments: This conference is held in honour of Prof. Dejan Raković's $65^{\text {th }}$ birthday.

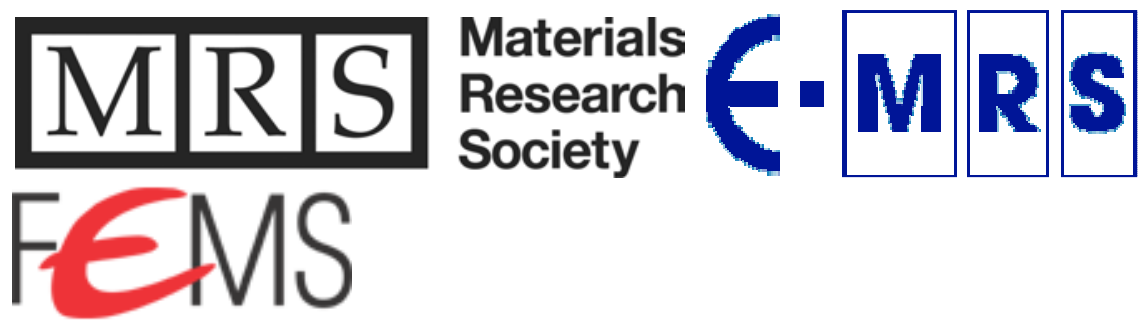

Printed in: $\quad$ Biro Konto

Sutorina bb, Igalo - Herceg Novi, Montenegro

Phones: +382-31-670123, 670025, E-mail: bkonto@t-com.me

Circulation: 220 copies. The end of printing: August 2016 
O.S.B.4.

\section{Activated track etched carbon for supercapacitor electrodes}

Petar Laušević, Predrag Pejović, Dragana Žugić, Yuri Kochnev, Pavel Apel and Zoran Laušević ${ }^{1}$ Laboratory of physical chemistry, Vinča institute of nuclear sciences, University of Belgrade, Serbia, ${ }^{2}$ School of Electrical Enginering, University of Belgrade, Serbia, ${ }^{3}$ Flerov laboratory of nuclear reactions, Joint institute for nuclear research, Dubna, Russia

A novel self-supporting carbon thin film supercapacitor electrode was developed starting from polyimide (Kapton) foil. In the first step of the electrode synthesis, latent tracks were inscribed in the starting polymer by irradiation with $253 \mathrm{MeV} \mathrm{Kr}$ ions. Next, cylindrical channels were formed by selective chemical etching with $\mathrm{NaOCl}$ along the ion tracks, creating track etched polymer. With subsequent carbonization and activation of the track etched polymer, activated track etched carbon was produced. A range of samples were obtained by varying the chemical etching time of the irradiated polymer. The influence of the chemical etching time on the electrochemical properties of the supercapacitor electrodes was investigated by cyclic voltammetry and electrochemical impedance spectroscopy.

O.S.B.5.

\section{The influence of fluorine doping on the structural and the electrical properties of $\mathrm{LiFePO}_{4}$ powder}

$\underline{\text { Dragana Jugović }}^{1}$, Miodrag Mitrićㄹ, Miloš Milović ${ }^{1}$, Nikola Cvjetićanin ${ }^{3}$, Bojan Jokić $^{4}$, Ana Umićević ${ }^{2}$, Dragan Uskoković ${ }^{1}$

${ }^{1}$ Institute of Technical Sciences of SASA, Knez Mihailova 35/IV, 11000 Belgrade, Serbia,

${ }^{2}$ Vinča Institute of Nuclear Sciences, University of Belgrade, P.O. Box 522, 11001 Belgrade, Serbia, ${ }^{3}$ Faculty of Physical Chemistry, University of Belgrade, Studentski Trg 12-16, P.O. Box 137, Belgrade, Serbia, ${ }^{4}$ Faculty of Technology and Metallurgy, University of Belgrade, Karnegijeva 4, 11000 Belgrade, Serbia

Low intrinsic electronic conductivity is the main weakness of $\mathrm{LiFePO}_{4}$ for the use as cathode material in lithium ion batteries. Here is presented an experimental proof of the theoretical prediction that fluorine doping of $\mathrm{LiFePO}_{4}$ can enhance its electrical conductivity. $\mathrm{LiFePO}_{4}$ and fluorine-doped $\mathrm{LiFePO}_{4}$ olivine type, carbon-free powders are synthesized and examined. Crystal structure refinements in the space group Pnma reveal that doping with fluorine ions preserves olivine structure with the reduction of both the lattice parameters and the antisite defect, and an increase of a crystallite size. A small amount of incorporated fluorine enhances electrical conductivity from $4.6 \times 10^{-7} \mathrm{Scm}^{-1}$ to $2.3 \times 10^{-6} \mathrm{Scm}^{-1}$ and has positive impact on the electrochemical performances. Several spectroscopy techniques (Mössbauer, FTIR, and Raman) disclose differences between two powders and additionally support the findings of both the Rietveld refinement and the conductivity measurements. 